\title{
OBITUARY
}

\section{OBITUARY FOR IVO MOLENAAR}

\author{
KLAAS SIJTSMA
}

TILBURG UNIVERSITY

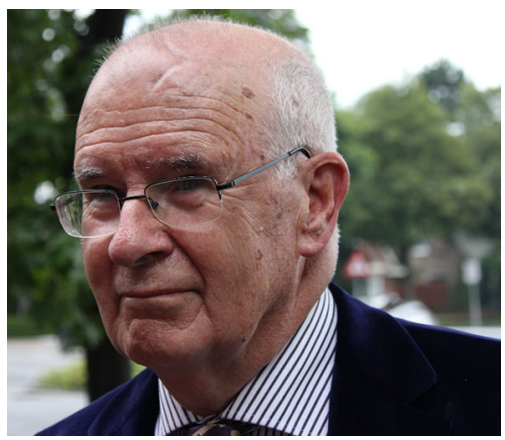

Ivo (official name Wouter) Molenaar passed away on February 26, 2018, at the age of 82. In this obituary, I will commemorate his teaching, his research, and his contributions to psychometrics and applied research. First, a brief bio.

Ivo started studying mathematics at the University of Amsterdam in 1958. His first job was at the Mathematical Centre in Amsterdam. His PhD dissertation (1970; also, see 1973) discussed simple approximations to the Poisson, binomial, and hypergeometric distributions, typical of the pre-computer era, and was a harbinger of his later work as a consultant in which he always looked for simple solutions that were correct, understandable to the researcher, and did justice to the noisy character of typical social science data. He defended his $\mathrm{PhD}$ dissertation in 1970. His supervisors were Jan Hemelrijk and Willem van Zwet, both renowned statisticians (e.g., Lehmann, 2008, pp. 261-268). After his doctorate, Ivo, his wife Ans, and their daughters went to the USA for ten months, where Ivo was a visitor at the Department of Statistics of the University of Pennsylvania. In December 1970, the University of Groningen called him at his US address and invited him to fly to the Netherlands and apply for a full professorship at the Faculty of Behavioral and Social Sciences. After a three-day stay, the University offered Ivo the job, which he accepted. Back in the Netherlands, Ivo started what would become a 29 -year outstanding career at the Faculty of Behavioral and Social Sciences of the University of Groningen. His chair was Statistical Analysis and Measurement Theory for the Social Sciences. He stayed in Groningen until his retirement in 2000 .

At Dutch universities, traditionally, newly appointed full professors present an inaugural address in which they unfold their view on the topic of their chair. In 1972, Ivo held his inaugural address, which was titled Dit is een uitdaging (This is a challenge). He discussed his views on knowledge acquisition in the social sciences, bridging the gap between statistics and the social sciences, the measurement of social science attributes by means of conjoint measurement and

Correspondence should be made to Klaas Sijtsma, Department of Methodology and Statistics, Tilburg University, Postbus 90153, 5000 LE Tilburg, The Netherlands. Email: K.Sijtsma@uvt.nl 
the probabilistic approaches proposed by Mokken and Rasch, the role of statistics in the social sciences, and misunderstandings about the possibilities of computers. He emphasized the importance of statistical consultation and its regular failure, often caused by researchers presenting their problems after they have collected their data rather than discussing their plans before collecting the data. Statistical consultation and support would become the common thread in his career. In his inaugural address, Ivo showed his versatility, which went far beyond statistics and psychometrics, and revealed his talent for eloquent speech. Whereas for us, lesser orators, presenting an inaugural lecture is tense and occasionally nerve-wrecking, Ivo held his by heart, talking for 45 min, explaining his audience that the spoken word has a greater effect than reading a written text aloud (1972).

This brings me to Ivo's quality as a teacher, and I will draw from my own memory to say something about it. The first time I saw Ivo was in 1978, when I was a third-year student attending "Statistics Continued," an elective course following obligatory statistics courses. Typically, Ivo discussed how to use statistics rather than outlining available methods and addressed topics such as statistical significance versus substantive relevance, and generalization from sample to sampling population, and next, the broader target population (also, 1977). Ivo was a nimble and lively lecturer, who spoke fluently in crystal-clear sentences and with wit, and his naturalness left no doubt that the problems he discussed were at the center of statistics. Here, for the very first time, someone convinced me that statistics could be playful and graceful rather than distant and bound to unescapable rules of logic and convention; that is, statistics could simply be great fun. Years later and initially much to my disbelief, Ivo told me that he prepared his classes in great detail and with intensive practice, and always felt extremely nervous before getting on stage. I took his confession as evidence that even great talent needs extensive training and maintenance before it comes to the fullest bloom.

In Amsterdam, Ivo started out as a theoretical statistician, but in Groningen, he gradually developed to become, as he called it, a statisticus practicus. This did not mean that his work was inaccurate but rather that he became heavily involved in what he thought social science researchers needed the most. In his view, these needs called for methods and corresponding advice consistent with the researchers' research problems and their own mastery of statistics. He learned much about the typical social and behavioral science problems from contemporaries, such as Wim Hofstee (University of Groningen) and Don Mellenbergh (University of Amsterdam). Adriaan de Groot (University of Amsterdam, later Groningen), possibly the first Dutch methodologist ever, published a monograph (De Groot, 1961) on the rules of methodology in psychological research that influences Dutch psychology until the present day, and which helped Ivo to find his way in the methodological thinking in the social and behavioral sciences.

In an interview he gave in 2016 (Wijsen, 2018), Ivo mentioned Melvin Novick (Lord \& Novick, 1968; Novick \& Jackson, 1974) as his greatest source of inspiration, both for his work in Bayesian statistics and the measurement of social science and psychological attributes by means of item response models. He invited Novick to come to Groningen to teach a course for interested colleagues and students. The course became a great success, and in the next years, each year Ivo invited a renowned statistician to guest lecture a course. These well-attended and much appreciated courses became part of the quickly expanding Dutch psychometric scene. Ivo was also much influenced by former fellow-student and colleague at the Mathematical Centre, Robert Mokken, who defended his PhD dissertation on nonparametric IRT in 1970 (published as Mokken, 1971).

Ivo was interested in several research topics. Starting in the 1970s, among others, he did research aimed at understanding and developing Bayesian statistics for the social sciences, and from the late 1970s, he published many articles and book chapters further developing Mokken's work (1997). He was the initiator in the late 1980s of the first PC version of the computer program MSP for Mokken scale analysis. He also did important work on the Rasch model (1983). With 
Gerhard Fischer, Ivo edited a book on the Rasch model (Fischer \& Molenaar, 1995). Ivo supervised $\mathrm{PhD}$ research in various statistical and psychometric domains. For example, he supervised $\mathrm{PhD}$ dissertations about Bayesian factor analysis, Bayesian methods in educational measurement, and the formalization of knowledge to specify subjective probability distributions, and later examples of PhD supervision entail dissertations about factor analysis, unfolding methods, structural equation modeling, association measures, observer agreement, mixed models, and item response theory. Moreover, he co-supervised several PhD dissertations on substantive topics in various research domains. The Web site Mathematics Genealogy Project mentions $60 \mathrm{PhD}$ dissertations Ivo supervised until 1999. However, looking through it, I noticed the later thesis of Marieke van Onna was missing, so that at least 61 is closer to the truth.

Ivo became interested in the Psychometric Society in the 1970s, and his expert opinion and talent for discussion in combination with his psychometric contributions drew the attention of many colleagues. He was the first non-American editor of Psychometrika from 1984 to 1988 . The Society's membership elected him President in 1997-1998, and his Presidential Address (1998) discussing robustness issues with respect to the choice of a statistical model was yet another example of his continuing concern about the correct use of statistics. His regular participation in Psychometric Society meetings influenced the views many colleagues had about psychometrics. In the 1980s, together with Don Mellenbergh, Edward Roskam, Wim van der Linden, and a few other Dutch colleagues, Ivo brought together the Dutch effort in psychometrics in a Dutch national graduate school known under the acronym of IOPS. With great persistence, mainly through demonstration of psychometrics results, they asked and then received attention for the remarkable progress Dutch psychometrics showed, and by doing this, they did wonders for the dissemination of Dutch psychometrics.

Ivo paired a broad knowledge of statistics and psychometrics with an unusual depth in many of the areas. In discussions, he responded quickly, sharply, and to the point. He enjoyed the game of science more than the results and could be extremely happy with a paper published in an outlet most colleagues nowadays would not consider seriously for their work. He was tireless pointing out that thinking before acting was the essence of good research and statistics. He called this "voordenken," a pun only Dutch readers will appreciate, but impossible to translate in English while maintaining the fun of it. At his retirement (2000), Ivo was honored with a liber amicorum titled Essays on Item Response Theory (Boomsma, Van Duijn, \& Snijders, 2001). He stayed active for a couple of years more and published work together with researchers from marketing and health research, and occasionally, psychometrics.

Perhaps his greatest contributions were twofold. First, for three decades he promoted a critical yet practical mentality in doing research and emphasized the responsible use of statistics, carefully not overstretching the researcher's possibilities. Second, with his colleagues, Ivo paved the way for Dutch psychometrics and put it in the international frontline. By doing this, he contributed to the broader internationalization of psychometrics and the Psychometric Society, no doubt further enriching the field. Together with his psychometric contributions, Ivo's meaning for psychometrics, psychometricians, and for dozens of applied researchers, his beloved "clients," is far beyond significance, for some immeasurable.

Ivo's wife, Ans, passed away in January 2016. Their four daughters survive him.

\section{References}

Boomsma, A., Van Duijn, M. A. J., \& Snijders, T. A. B. (2001). Essays on item response theory. New York, NY: Springer. De Groot, A. D. (1961). Methodologie (Methodology). Den Haag, The Netherlands: Mouton.

Fischer, G. H., \& Molenaar, I. W. (1995). Rasch models. Foundations, recent developments, and applications. New York, NY: Springer.

Lehmann, E. L. (2008). Reminiscences of a statistician. The company I kept. New York, NY: Springer Science+Business Media LLC.

Lord, F. M., \& Novick, M. R. (1968). Statistical theories of mental test scores. Reading, MA: Addison-Wesley. 
Mathematics Genealogy Project. Ivo Wouter Molenaar, list of PhD students who defended their dissertation. Retrieved 17 March 2018 from http://www.genealogy.ams.org/id.php?id=75548.

Mokken, R. J. (1971). A theory and procedure of scale analysis. The Hague, The Netherlands: Mouton/Berlin, Germany: De Gruyter.

Molenaar, I. W. (1970). Approximations to the Poisson, binomial and hypergeometric distribution functions. MC Tract 31. Amsterdam: Mathematisch Centrum (now: Centrum voor Wiskunde en Informatica).

Molenaar, W. (1972). Dit is een uitdaging (This is a challenge). Inaugural lecture, 1 February 1972. Rijksuniversiteit Groningen, The Netherlands.

Molenaar, I. W. (1973). Simple approximations to the Poisson, Binomial and Hypergeometric distributions. Biometrics, 29, 403-407.

Molenaar, W. (1977). Ik word ziek van de statistiek, of: er van weten zonder er naar te handelen (Statistics makes me sick, or: knowing without acting). Mens \& Maatschappij, 52(1), 58-71.

Molenaar, I. W. (1983). Some improved diagnostics for failure of the Rasch model. Psychometrika, 48, 49-72.

Molenaar, I. W. (1997). Nonparametric models for polytomous items. In W. J. van der Linden \& R. K. Hambleton (Eds.), Handbook of modern item response theory (pp. 369-380). New York, NY: Springer.

Molenaar, I. W. (1998). Data, model, conclusion, doing it again. Psychometrika, 63, 315-340.

Molenaar, I. W. (2000). Vast versus variabel. De statistische splitsing (Fixed versus variable. The statistical division). Valedictory address, 12 September 2000, University of Groningen, The Netherlands.

Novick, M. R., \& Jackson, P. H. (1974). Statistical methods for educational and psychological research. New York, NY: McGraw-Hill.

Wijsen, L. D. (2018). Interview Ivo Molenaar, 6 July 2016. University of Amsterdam, The Netherlands: Unpublished transcript.

Published Online Date: 30 APR 2018 